\title{
Governance of the Exploration of Subglacial Antarctica
}

\author{
Martin John Siegert ${ }^{1 *}$ and Mahlon C. Kennicutt $I^{2}$ \\ 1 Grantham Institute and Department of Earth Science and Engineering, Imperial College London, London, United Kingdom, \\ ${ }^{2}$ Department of Oceanography, Texas A\&M University, College Station, TX, United States
}

OPEN ACCESS

Edited by:

John F. Burkhart,

University of Oslo, Norway

Reviewed by:

Zoe Courville,

Cold Regions Research and Engineering Laboratory, United States Alex Oriel Godoy,

Universidad del Desarrollo, Chile

*Correspondence:

Martin John Siegert m.siegert@imperial.ac.uk

Specialty section:

This article was submitted to Interdisciplinary Climate Studies,

a section of the journal

Frontiers in Environmental Science

Received: 17 May 2018

Accepted: 24 August 2018

Published: 12 September 2018

Citation:

Siegert MJ and Kennicutt MC II (2018)

Governance of the Exploration of Subglacial Antarctica.

Front. Environ. Sci. 6:103.

doi: 10.3389/fenvs.2018.00103
Subglacial lakes, and their surrounding aqueous environments, are known to be viable yet extreme habitats for microbial life that may hold records of climate change spanning hundreds of thousands of years. Since the detection of Lake Vostok in 1996 plans have been developed to access, sample, and monitor these unique environments. Critical to these plans is assurance that contamination and disturbance is minimized in all aspects of the activity. Precisely how this is achieved has been a matter of international debate for many years culminating in the formulation of a "Code of Conduct" to guide responsible scientific exploration and stewardship of these pristine systems by the Scientific Committee on Antarctic research. The Code of Conduct was first introduced to the Antarctic Treaty Consultative Meeting in 2011, influencing planning for three exploration programs. In May 2018, following several recent and operational advances, Antarctic Treaty Parties agreed to its use and dissemination, ensuring that subglacial lakes exploration and access is undertaken in a responsible, defensible, and fact-based manner. As our knowledge of subglacial lakes improves, so too will our appreciation of their scientific value and potential vulnerability. In other regions of Antarctica where value and vulnerabilities are high, Antarctic Specially Protected Areas and Antarctic Specially Managed Areas ensure long-term protection whilst allowing scientific access and study. Such governance models will be applicable to the conservation and protection of subglacial lake systems as scientific understanding of their form and functioning advances.

Keywords: subglacial lakes, environmental protection, Antarctic treaty, subglacial environments, hot water drilling

\section{INTRODUCTION: BACKGROUND AND SCIENTIFIC INTEREST IN SUBGLACIAL LAKES}

Antarctic subglacial lakes are bodies of water that lie underneath the polar ice sheet (Siegert, 2005). They can be detected by geophysical techniques, and exist because background levels of geothermal heating is sufficient to allow the ice-sheet base to melt in many regions of Antarctica. Over 400 lakes have been discovered, scattered broadly across the continent (Siegert et al., 2016).

The first discovery of an Antarctic subglacial lake at Sovetskya Station in the late 1960s (Figure 1) remained a relatively obscure observation until the mid-1990s (Robin, 1969). In 1996 serious scientific interest was engendered as a consequence of two findings. The first was delineation of the dimensions of one particular lake, now known as Lake Vostok, which is the largest lake beneath an ice sheet on our planet. Covered by more than $4 \mathrm{~km}$ of ice, Lake Vostok is over $200 \mathrm{~km}$ in length, $80 \mathrm{~km}$ in width and, at one location, is filled with water to a depth of more than $500 \mathrm{~m}$ 


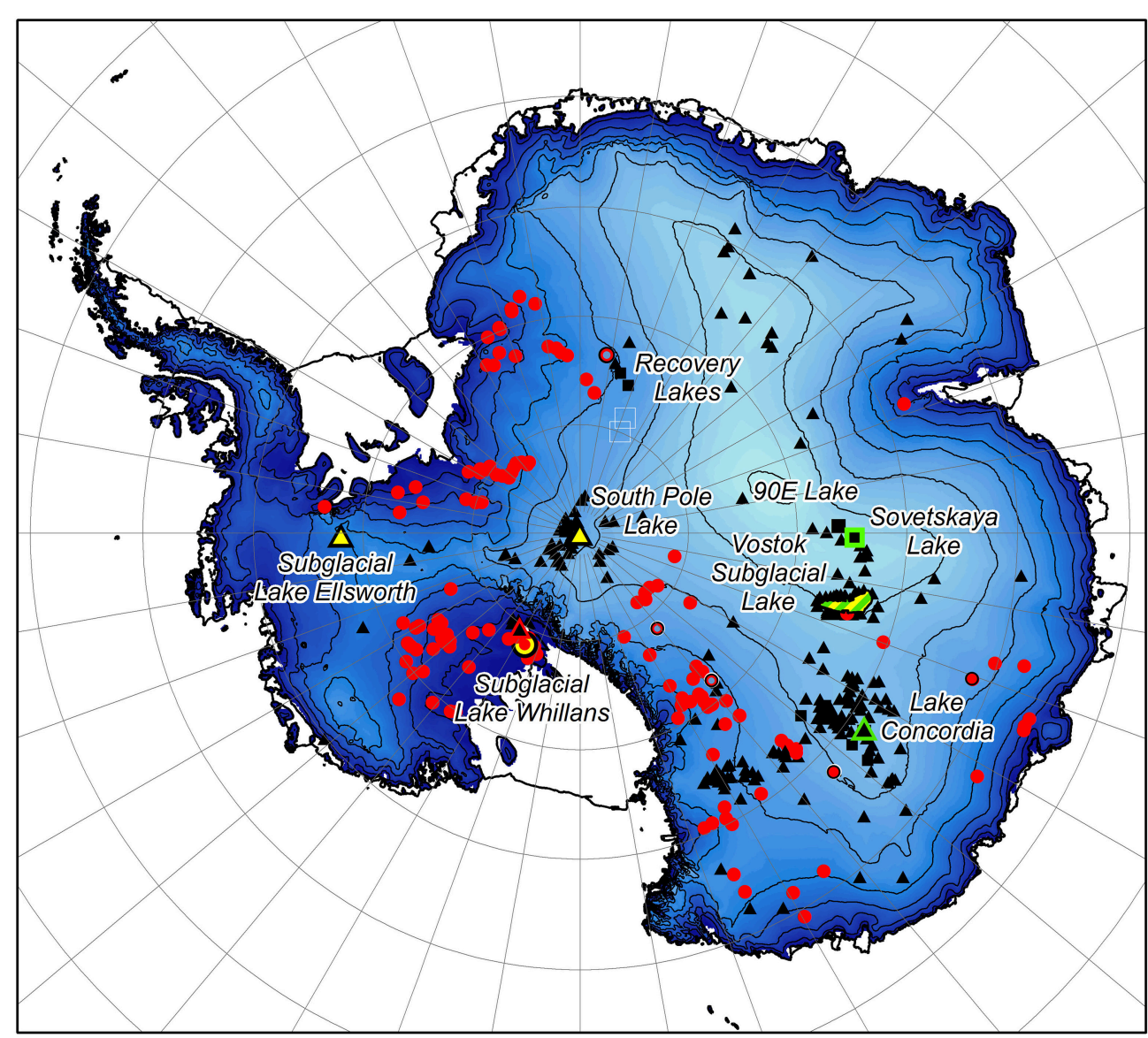

FIGURE 1 | Map of Antarctica showing the locations of all subglacial lakes included in the 2012 Inventory (Wright and Siegert, 2012). Colors/shapes indicate the type of investigations undertaken at each site: Black/triangle, Radio Echo Sounding; yellow, seismic sounding; green, gravitational field mapping; red/circle, surface height change measurement; square, shape identified from ice surface feature. Lake Vostok is shown in outline.

(Kapitsa et al., 1996). The second was the identification of at least 77 other smaller lakes (Siegert et al., 1996). At this time, microbiologists began to speculate about the types of life that these remote lakes might contain given that some of them had likely not seen daylight for more than 14 million years. If life was present from the onset of isolation, or evolved in place, novel adaptions would be essential for survival and propagation in such extreme, dilute, low energy/carbon environments (EllisEvans and Wynn-Williams, 1996). In addition, climate scientists wondered whether unique records of past ice-sheets and environmental change might exist in sediments below these lakes in the interior of the continent. This exciting hypothesis raised the possibility that lake-floor sediment records could overlap with ice-core records ( $\sim 1$ million years ago) potentially extending a continuous climate record by hundreds of thousands, if not millions, of years (Bentley et al., 2011; Hodgson et al., 2016). Astrobiologists also began to suggest that Antarctic subglacial lakes were Earth-bound analogs that could serve as test beds to develop the technologies needed to explore newly discovered deep-space icy-water environments such as those on Europa-a moon of Jupiter (Cockell et al., 2011), or the beneath the Southern Polar Ice Cap of Mars (Orosei et al., 2018). The challenge was that for these truly cutting-edge scientific possibilities to become a reality, expensive and complex projects to physically access lakes would need to be undertaken.

This interest led immediately to the development of ideas about how to explore and access subglacial lakes, with an initial emphasis on Lake Vostok. Such a program would need to drill through $\sim 4 \mathrm{~km}$ of ice cover, analyze in situ properties, sample lake water, penetrate and retrieve sediment, and capture biological samples (Priscu et al., 2003). Scientific goals were expansive and included testing of hypotheses about life in the lakes and elsewhere, in and beyond our solar system, and deciphering previously unavailable records of Earth's climate change. However, discussions were tempered by the realization that the exploration and sampling of subglacial lakes must be cognizant that these features are unique and irreplaceable environments that have been disconnected from the rest of the planet for potentially millions of years (Siegert et al., 2001). Therefore, exploration would have to be accomplished 
"cleanly" while minimizing disturbance and contamination. In the late 1990s, such demands appeared challenging, given that conservation and stewardship of subglacial systems had not been fully considered, and that existing techniques to drill deep into ice commonly used kerosene-based antifreezes that would undoubtedly pose environmental threats.

In the early 2000s, the Scientific Committee on Antarctic Research (SCAR) considered subglacial environments worthy of international discussion and agreement, and convened a group of specialists. From this a Scientific Research Programme, entitled SALE (Subglacial Antarctic Lake Environments) was initiated. SALE served for 6 years as a forum for international dialog on subglacial exploration plans, techniques and developments and led to the convening of an international symposium with about 80 attendees to further develop plans (Grenoble, April 2006).

Three projects began to emerge-a long standing Russian ice core project's extension into Lake Vostok (Lukin and Bulat, 2011); a UK-led mission to a newly discovered lake called Lake Ellsworth (Siegert et al., 2012); and a US-led study on so-called "active" lakes in West Antarctica, where water feeds into, and out of, lakes near the ice-sheet margin from an upstream hydrological catchment (Priscu et al., 2013).

\section{ASSESSMENT OF GUIDELINES ON THE EXPLORATION OF SUBGLACIAL LAKES}

As the plans for subglacial lake exploration progressed (e.g., Siegert et al., 2007), the US National Academies of Science issued a report that considered, for the first time, the preconditions to be met in order to conduct in an environmentally-sound exploration program (US National Research Council, 2007). The report acted as an independent assessment of what SALE had considered to this point but, while it made reference to a variety of ways in which cleanliness could be achieved, it did not attempt to offer preferred solutions nor quantification of the problem. The US-NRC report posed a number of questions that required answers prior to direct subglacial access. For example, what is the definition of "cleanliness" in measurable parameters? What concentrations (or total loads?) of introduced microbes and chemicals are acceptable? What are realistic limitations on our ability to clean instruments and measure microbes? How does one measure and quantify the "cleanliness" of an experiment? How does one conduct monitoring to establish whether the lake was "contaminated" post-entry?

So, while there was agreement on high-level issues, such as the general avoidance of contamination, there were no quantifiable standards of cleanliness, no agreement on how such standards might be achieved (from the perspectives of clean drilling, instrumentation, and operations), and no consensus on how to monitor "cleanliness" during and after the completion of a project. Scientific drivers for cleanliness were recognized as operational protocols and would be needed to sample and detect ultra-low levels of chemicals and biota without introducing unwanted material from the surface, as it would compromise the integrity of samples (Doran and Vincent, 2011). Early studies of lake water refrozen to the base of the ice sheet over Lake Vostok were controversial and many considered the results to be artifacts of suboptimal retrieval techniques, including submersion in the kerosene-based borehole drilling fluid, that were not designed to recover pristine microbiological samples (Priscu et al., 1999). Lessons were available from analogous internationally-agreed standards for inter-planetary exploration missions, codified as planetary protection guidelines (e.g., COPSPAR, https://planetaryprotection.nasa.gov/overview).

One stipulation made by the US-NRC report was that a Comprehensive Environmental Evaluation (CEE) of the project be undertaken, and debated by Antarctic Treaty Parties (through its Committee on Environmental Protection, CEP) before a subglacial lake exploration mission could take place (Doran and Vincent, 2011). In that way, the international community could inspect and judge whether a project met cleanliness requirements set out in the US-NRC report and other standards developed by individual nations. In the UK at least, a permit to conduct the work would only be offered if a CEE was conducted and reviewed at the Treaty level. So, it became important to understand precisely what was meant by "contamination," how it was to be measured and how it was to be avoided.

SCAR offered a way forward in 2011, through the introduction of an internationally-agreed "Code of Conduct," formulated by a panel of scientists and technologists independent of its SALE group (as several of its members were actively pursuing exploration programs and, hence, were conflicted) and widely peer-reviewed by the community (SCAR, 2011). The code was based on the premise that subglacial lakes, or subglacial aqueous environments more generally, are likely unique systems harboring microbes living in extreme conditions, and that water beneath the ice was likely "freely flowing," meaning that hydrological connections between lakes and across the icesheet base were to be expected. To safeguard these unique environments, SCAR deemed that plans for their exploration should be characterized by international inspection, as follows: (1) the exploration of subglacial lakes should adhere to the Protocol on Environmental Protection within the Antarctic Treaty and be reviewed by its CEP, so that any program "minimizes their possible damage and contamination, and protects their value for future generations, not only in terms of their scientific value but also in terms of conserving and protecting these pristine environments"; (2) all proposed exploration plans should undergo an environmental impact assessment, involving an Initial Environmental Evaluation (IEE) for the direct access to any subglacial system, noting that a "CEE may be the appropriate level of assessment given the potential impacts expected from such an activity"; and (3) any CEE, which must cover all aspects of the project from the footprint of surface support facilities to the deployment of equipment into the lake, should be scrutinized and commented on by the CEP-allowing plans to be open and accepted or challenged by the wider community. In other words, plans for subglacial lake exploration, and indeed wider subglacial environment access, should be planned in a manner consistent with environmental protection, fully open to international scrutiny, discussion, and input. 
The way in which environmental protection, and international agreement on the plans, should be achieved was left open, acknowledging that different options would be considered dependent on the designs and objectives of individual projects. However, for the exploration of deep-water lakes within the ice-sheet interior, which have likely been isolated from the atmosphere for millions of years, there was an expectation that environmental protection could only be achieved by an ultraclean experiment, ensuring that minimal surface contamination enters and remains in the lake. Disturbance of in situ materials was also a concern as some of these lakes have experienced quiescent conditions for at least thousands of years and the mixing of stratified water columns and resuspension of sediments might cause alteration of the pristine conditions (similar disturbances in the early exploration of McMurdo Dry Valley lakes was noted http://www.mcmlter.org/conferences/ dvenvrn98.html).

Drilling fluids (needed to bore through the $3-4 \mathrm{~km}$ thick ice) should be "cleaned to the extent practicable, and records should be maintained of sterility tests" and, that they "should not contain more microbes than are present in an equivalent volume of the ice that is being drilled through to reach the subglacial environment" (SCAR, 2011). In summary, the code of conduct stated that "the total amount of any contaminant added to these aquatic environments [during an exploration mission] should not be expected to change the measurable chemical properties of the environment"; noting also that measurements are only as effective as the detection limits of the methodologies utilized.

In addition, once in the lake, any exploration program should act to minimize disruption to the environment, avoiding unwanted mixing of lake water, and disturbance of basal sediment, noting that equipment entering the lake should be "meticulously" cleaned to avoid contamination. Again, how this could be achieved was left open to individual projects to justify.

A final element of the Code of Conduct stipulated that it should be updated as "new scientific results and environmental impact reports become available from planned ... exploration campaigns." There was a recognition that technologies and scientific questions evolve with time and today's non-issues (or non-detectable disturbances) might be seen as problematic for future (yet to be determined) scientific goals. The SCAR code of conduct was discussed at, and supported by, the 34th Antarctic Treaty Consultative Meeting in Buenos Aires from 20th June to 1st July 2011.

\section{THREE EXPLORATION PROGRAMS}

By 2011, the three scientific programs noted earlier were at mature stages of development; (1) Russia planned to use the existing $3.5 \mathrm{~km}$ deep ice-core borehole at Vostok Station to access Lake Vostok (Lukin and Bulat, 2011); (2) the UK proposed to use hot-water drilling to explore the $160 \mathrm{~m}$ deep Lake Ellsworth at the center of West Antarctica (Siegert et al., 2012); and (3) the US planned to access and sample Lake Whillans, an ephemeral subglacial lake at the edge of the West Antarctic ice sheet, using hot-water drilling (Priscu et al., 2013). CEEs were developed and submitted to the Antarctic Treaty for both the Russian [starting with a draft CEE in 2003, followed by a series of Information Papers in subsequent years] and UK plans (https:// www.bas.ac.uk/wp-content/uploads/2015/05/subglacial_lake_ ellsworth_final_cee.pdf; Lake Ellsworth Consortium, 2012). The US program decided, since the ice-sheet had been previously accessed multiple times in the vicinity of Lake Whillans, that a CEE was not required.

The procedure for lodging a CEE requires it to be done well ahead of the planned activity, to allow parties sufficient time to read and comment on the plans. During Treaty meetings comments are received by the submitting nation and either responded to immediately, or at a later time. Hence, after iteration, the CEE can be agreed by all parties as being compliant with the SCAR Code of Conduct. Once this is done satisfactorily, at least from the point of view of the UK, a "permit" to conduct the work can be issued. However, it should be noted that plans and responses to issues raised are only commented on and not "approved", relying on peer-pressure as the only enforcement mechanism.

For the Lake Ellsworth program, a CEE was formulated by the British Antarctic Survey (BAS), detailing all aspects of the exploration mission and presented at the XXXIV Antarctic Treaty Consultative Meeting (ATCM)-CEP XIV in Buenos Aires, Argentina (June 2011). The CEE explained how drilling contamination would be minimized through: (1) the use of a hotwater drill that essentially pasteurized and filtered water from surface snow, making it cleaner than the glacier ice being melted into; (2) medical-level cleanliness procedure (e.g., autoclave) for all equipment entering the lake; and (3) field procedures that prevented exposure of equipment to the atmosphere prior to deployment into the lake. The Lake Ellsworth CEE was revised a year later at the XXXV ATCM-CEP XV in Hobart Australia (June, 2012) (Lake Ellsworth Consortium, 2012; Siegert et al., 2012). At this point, the CEE was deemed acceptable by the UK government, in light of comments received and subsequent modifications made, and a permit for the fieldwork was awarded. Again, there is no international enforcement mechanism and approval is the remit of the national authorities within the countries proposing a project.

The outcomes of the three exploration missions have been discussed previously (Siegert, 2018). Lake Vostok was accessed by the ice core drill in February 2012, though contamination of retrieved samples remained an issue. The UK mission to Lake Ellsworth failed as a consequence of problems with its hotwater drill and the lake was not entered (Siegert et al., 2014). The US-Lake Whillans experiment was successful in sampling water and measuring microbial life beneath the ice (Tulaczyk et al., 2015). An international meeting was held at the Royal Society's Chicheley Hall in March 2015 to discuss these first three exploration missions, and to share future plans for ongoing and future exploration programs (Siegert et al., 2016).

In May 2017, as a consequence of numerous advances in understanding of subglacial lake systems [e.g., that over 400 subglacial lakes existed in Antarctica (Figure 1), that Greenland also contained some subglacial lakes at its margin (Palmer et al., 2013), and subglacial lakes constitute a wide-variety 
of distinct environments beneath polar ice masses (Siegert, 2016)], the SCAR code of conduct was updated and submitted to the ATCM XL-CEP XX in Beijing, China. At the 2018 ATCM a final decision was made to "adopt the SCAR Code of Conduct for the Exploration and Research of Subglacial Aquatic Environments by means of Resolution." In the resolution, it recommends "endorsement of this Code of Conduct by the CEP ... encouraging the use and dissemination of this code."

\section{ACTIONABLE RECOMMENDATIONS AND CONCLUSIONS}

Several new plans are proposed for subglacial lake exploration including those by Chile, South Korea, and China, as well as ongoing missions to Lake Vostok, Lake Ellsworth, and the Lake Whillans system. It is expected that more missions to explore subglacial lakes will be planned in future. Some of the most compelling scientific questions will only be addressed when a representative set of subglacial environments are accessed and sampled. Adherence to the SCAR Code of Conduct will ensure that these unique environments are examined in a scientifically valid way that allows both their protection and ensures the success of future missions.

As subglacial lake research is in its infancy (despite having a 60 year history, Siegert, 2018), evidence necessary to demonstrate the scientific value of subglacial aqueous environments is only just beginning to form. At the moment, for the exploration of likely ancient systems beneath the center of the ice sheet, the international community agrees that strict adherence to the SCAR Code of Conduct be upheld by the CEP through assessment of CEEs. However, for ephemeral lakes near to the edge of the continent, and as a consequence of previous subglacial access, a less rigid approach is followed, involving IEESs rather than CEEs. This approach leads to incremental advances in our appreciation of subglacial lakes and their hydrological systems, and careful planning of more ambitious scientific targets.

In some regions of Antarctica, which have been demonstrated to hold significant and unique scientific value and also environmental vulnerability, enhanced levels of internationallyaccepted protection are put in place. Two governance mechanisms, through the Antarctic Treaty, are available: Antarctic Specially Protected Areas (ASPAs) and Antarctic Specially Managed Areas (ASMAs). As a part of the interior of

\section{REFERENCES}

Bentley, M. J., Christoffersen, P., Hodgson, D. A., Smith, A. M., Tulaczyk, S., and Le Brocq, A. M. (2011). "Subglacial lake sediments and sedimentary processes: potential archives of ice sheet evolution, past environmental change, and the presence of life," in Subglacial Antarctic Aquatic Environments, eds M. Siegert, C. Kennicutt, and B. Bindschadler (Washington, DC: AGU Geophysical Monograph 192), 83-110.

Cockell, C. S., Bagshaw, E., Balme, M., Doran, P., McKay, C. P., Miljkovic, K., et al. (2011). "Subglacial environments and the search for life beyond the earth," in Subglacial Antarctic Aquatic Environments, eds M. Siegert, C. Kennicutt, the Antarctic continent, conservation and protection measures for subglacial systems should be required to adhere to the same international process and protocols as the rest of the continent-customized to the special values and settings of these environments.

Under an ASPA, it is an offense to enter a site without a Permit, which must be applied for at the same time as the submission of an EIA (usually to an individual nations Foreign Office or State Department). Each ASPA has an internationally agreed management plan, and any proposed activity must be in accordance with it. All visits to an ASPA must be recorded and reported to ensure international visibility of work conducted there. ASMAs cover regions in which there are visible plans and coordination of activities that help to avoid of conflicts, improve cooperation between national programs and minimize environmental impact. Unlike ASPAs, no Permit is needed to enter an ASMA.

The relevance of ASPAs and ASMAs to subglacial lake environments has been debated since the US-NRC report in 2007. An example of how they work well together is in the Dry Valleys of East Antarctica, which were first visit by Scott's expedition in 1912. Here, the whole region of the Dry Valleys come under the governance of an ASMA. However, specific elements of it, such as Blood Falls in the Lower Wright Glacier, have been awarded a specific ASPA. This combination of governance tools allows appropriate scientific access to an important region, with enhanced protection of specific sites. In future, as more scientific evidence becomes available, it may be that subglacial hydrological catchments may be best preserved under ASMAs, with individual upstream sites (e.g., subglacial lakes) being given ASPA status. Before this is possible, a basic understanding of subglacial systems is required, and this can only come from carefully-designed and environmentally responsible direct access experiments.

\section{AUTHOR CONTRIBUTIONS}

All authors listed have made a substantial, direct and intellectual contribution to the work, and approved it for publication.

\section{FUNDING}

MS acknowledges funding for the Lake Ellsworth program from the UK Natural Environment Research Council grants G00465X/1, G00465X/2, and G00465X/3. 
Antarctic subglacial settings. Philos. Trans. R. Soc. Lond. A 374:20150056. doi: 10.1098/rsta.2015.0056

Kapitsa, A., Ridley, J. K., Robin, G., de, Q., Siegert, M. J., and Zotikov, I. (1996). Large deep freshwater lake beneath the ice of central East Antarctica. Nature 381, 684-686.

Lake Ellsworth Consortium (2012). Available online at: https://www.bas.ac.uk/wpcontent/uploads/2015/05/subglacial_lake_ellsworth_final_cee.pdf

Lukin, V., and Bulat, S. (2011). "Vostok subglacial lake: details of Russian plans/activities for drilling and sampling," in Antarctic Subglacial Aquatic Environments, AGU Geophysical Monograph Series 192, eds M. J. Siegert, M. C. I. Kennicutt, and R. A. Bindschadler (Washington, DC: American Geophysical Union), 187-197.

Orosei, R., Lauro, S. E., Pettinelli, E., Cicchetti, A., Coradini, M., Cosciotti, B., et al. (2018). Radar evidence of subglacial liquid water on Mars. Science 25:eaar7268. doi: $10.1126 /$ science.aar7268

Palmer, S., Dowdeswell, J. A., Christoffersen, P., Young, D., Blankenship, D. D., Greenbaum, J., et al. (2013). Greenland subglacial lakes detected by radar. Geophys. Res. Lett. 40:058383. doi: 10.1002/2013GL058383

Priscu, J. C., Achberger, A. M., Cahoon, J. E., Christner, B. C., Edwards, R. L., Jones, W. L., et al. (2013). A microbiologically clean strategy for access to the Whillans Ice Stream subglacial environment. Antarct. Sci. 25, 637-647. doi: 10.1017/ S0954102013000035)

Priscu, J. C., Adams, E. E., Lyons, W. B., Voytek, M. A., Mogk, D. W., Brown, R. L., et al. (1999). Geomicrobiology of subglacial ice above Lake Vostok, Antarctica. Science 286, 2141-2144.

Priscu, J. C., Bell, R. E., Bulat, S. A., Ellis-Evans, J. C., Kennicutt, M. C. I. I., Lukin, V. V., et al. (2003). An international plan for Antarctic subglacial lake exploration. Polar Geogr. 27, 69-83. doi: 10.1080/789610223

Robin, G. Q. (1969). Antarctic RES. Philos. Trans. Royal Soc. 265A, 437-505.

SCAR (2011). Available online at: https://www.scar.org/scar_media/documents/ science/atcm34_ip033_CofC_SAEs.pdf

Siegert, M. J. (2005). Lakes beneath the ice sheet: the occurrence, analysis \& future exploration of Lake Vostok \& other Antarctic subglacial lakes. Ann. Rev. Earth Planet. Sci. 33, 215-245. doi: 10.1146/annurev.earth.33.092203. 122725

Siegert, M. J. (2016). A wide variety of unique environments beneath the Antarctic ice sheet. Geology 44, 399-400. doi: 10.1130/focus052016.1

Siegert, M. J. (2018). "A 60-year international history of Antarctic subglacial lake exploration," in Exploration of Subsurface Antarctica: Uncovering Past Changes and Modern Processes, eds M. J. Siegert, S. S. R. Jamieson, and D. A. White (London: Geological Society, Special Publications), 461.
Siegert, M. J., Behar, A., Bentley, M., Blake, D., Bowden, S., Christoffersen, P., et al. (2007). The exploration of Ellsworth Subglacial Lake: a concept paper on the development, organisation and execution of an experiment to explore, measure and sample the environment of a West Antarctic subglacial lake. Rev. Environ. Sci. Biotechnol. 6, 161-179. doi: 10.1007/s11157-006-9109-9

Siegert, M. J., Clarke, R. J., Mowlem, M., Ross, N., Hill, C. S., Tait, A., et al. (2012). Clean access, measurement and sampling of Ellsworth Subglacial Lake: a method to explore deep Antarctic subglacial lake environments. Rev. Geophys. 50:RG1003. doi: 10.1029/2011RG000361

Siegert, M. J., Dowdeswell, J. A., Gorman, M. R., and McIntyre, N. F. (1996). An inventory of Antarctic sub-glacial lakes. Antarctic Sci. 8, 281-286.

Siegert, M. J., Ellis-Evans, J. C., Tranter, M., Mayer, C., Petit, J. R., Salamatin, A., et al. (2001). Physical, chemical and biological processes in Lake Vostok and other Antarctic subglacial lakes. Nature 414, 603-609. doi: 10.1038/414603a

Siegert, M. J., Makinson, K., Blake, D., Mowlem, M., and Ross, N. (2014). An assessment of deep-hot-water drilling as a means to undertake direct measurement and sampling of Antarctic subglacial lakes: experience and lessons learned from the Lake Ellsworth field season 2012-13. Ann. Glaciol. 55, 59-73. doi: 10.3189/2014AoG65A008

Siegert, M. J., Priscu, J., Alekhina, I., Wadham, J. L., and Lyons, W. B. (eds.). (2016). Antarctic subglacial lake exploration: first results and future plans. Trans. $R$. Soc. Lond. A 374:20140466. doi: 10.1098/rsta.2014.0466

Tulaczyk, S., Mikucki, J. A., Siegfried, M. R., Priscu, J. C., Barcheck, C. G., Beem, L. H., et al. (2015). WISSARD at Subglacial Lake Whillans, West Antarctica: scientific operations and initial observations. Ann. Glaciol. 55:2014. doi: 10.3189/2014AoG65A009

US National Research Council, (2007). Exploration of Antarctic Subglacial Aquatic Environments: Environmental and Scientific Stewardship. Washington, DC: US National Academy of Sciences.

Wright, A. P., and Siegert, M. J. (2012). A fourth inventory of Antarctic subglacial lakes. Antarctic Sci. 24, 659-664. doi: 10.1017/S095410201200048X

Conflict of Interest Statement: The authors declare that the research was conducted in the absence of any commercial or financial relationships that could be construed as a potential conflict of interest.

Copyright $\odot 2018$ Siegert and Kennicutt. This is an open-access article distributed under the terms of the Creative Commons Attribution License (CC BY). The use, distribution or reproduction in other forums is permitted, provided the original author(s) and the copyright owner(s) are credited and that the original publication in this journal is cited, in accordance with accepted academic practice. No use, distribution or reproduction is permitted which does not comply with these terms. 